\section{RESEARCH LEITERS}

Effects of fatigue on ankle stability and proprioception in university sportspeople

\section{0 bjectives}

To assess the effect of fatigue from sporting activity on ankle stability and proprioception in students at the University of Southampton. A wide range of sporting activity was included from taekwon-do to indoor football.

\section{$M$ ethods}

Subjects were recruited from Southampton University sports facilities. They agreed to perform two dynamic tests before and after they took part in sport. (1) A horizontal hop starting and finishing on the same foot. The best distance from three attempts was recorded. (2) A hexagonal hop test: the subjects hopped around a hexagon marked on the ground in either a clockwise or anticlockwise direction as quickly as possible. The quickest attempt out of three was recorded.

Results

The means before and after exercise were compared using a Student's t test. Both tests were set at the $5 \%$ significance level.

Hexagonal hop test $(n=40)$

A Student's t test was used to compare the best time for the hexagonal hop test before and after exercise. The $t$ value was 3.95 , indicating a significant improvement in hop time after exercise.

Horizonal hop test $(n=25)$

At the $5 \%$ level, the data are insignificant, with a $t$ value of 0.1107 . A general trend of increased distance after exercise (fatigue) was observed (mean of $1.746 \mathrm{~m}$ before against $1.775 \mathrm{~m}$ after)

\section{Conclusions}

The results show that the subjects made significant improvements in hexagonal hop times with no difference in the distance hopped. This leads to the conclusion that despite muscular fatigue, ankles appear to be more stable after exercise. Does exercise induce an increase in afferent/efferent nerve impulses to and from muscle spindles around the ankle leading to improved joint position sense?

J P Brown, G W Bowyer University of Southampton M edical Schoo Southampton $\mathrm{G}$ eneral Hospital, Tremona road, Southampton S0 16 6YD, UK; jpb298@soton.ac.uk

\section{Centripetal skater's manual oedema}

This doctor's indulgence in rigorous physical activity led to the realisation of a novel clinical entity. As an active sportsman and ex-ice hockey player, currently living in a hot climate, I have had to sublimate my sporting activities to infrequent inline roller skate street journeys. Recently, on a day of a very pressed schedule, I attempted to concentrate a week's exercise into one concise session. After an hour and fifteen minutes of intense exertion, rapidly skating up and down hills and valleys, over good and not so good paved surfaces, I experienced an unexpected heaviness and tightness in the tips of my fingers. Later I noticed that the simple task of clenching my fists was not fully possible, and this was more accentuated in the right hand (the more dominant of the two). Within the course of a couple of hours the whole condition spontaneously subsided.

I had never previously suffered such events, no concurrent pathology existed in any body system, and I have remained healthy since. The working hypothesis to explain this phenomenon must be that the rhythmic swaying and waving of the outstretched arms in a circular arc resulted in increased centripetal force of hydrostatic pressure in the distal parts of the upper limbs. This overwhelming pressure overcame the compensation mechanism of the lymphatic system to drain the hands. Axillary pressure from the straps of a small backpack carried during the whole journey may have compounded the effect, although all it contained was a mobile telephone and a small bottle of water.

Bizarre and not always innocent diagnoses have been made in the pathogenesis of limb oedema. ${ }^{12}$ The resulting hydrostatic effects of physical exertion of the lower limbs are wel documented. ${ }^{3-5}$ Possible reasons why this problem does not occur during ice skating are the fact that long distances without any stops are uncommon and the cold environment may provide protection through peripheral vasoconstriction.

Thus heavy roller skating is a thought to entertain a doctor's mind when confronted with a patient with acute unexplained bilateral hand oedema.

S Naimer

Department of Emergency M edicine, $N$ eve Dekalim, Goosh Katif, Israel 79779 ; sody@thecomp.com

\section{References}

1 Skerker RS, Flandry FC. Related articles case presentation: painless arm swelling in a high school football player. Med Sci Sports Exerc 1992;24:1185-9.

2 Stick C, Jaeger H, W itzleb E. M easurements of volume changes and venous pressure in the human lower leg during walking and running. J Appl Physiol 1992;72:2063-8.

3 Holland DL, Swenson W M, Tudor RB, et al. A compartment syndrome of the upper arm. A case report. Am I Sports Med

$1985: 13: 363-4$

4 Vaananen I, Mantysaari M, Huttunen $P$, et al. The effects of a 4 -day march on the lower extremities and hormonal balance. Mil Med 1997:162:118-22.

5 Cloughley WB, Mawdsley RH. Effect of running on volume of the foot and ankle. $J$ Orthop Sports Phys Ther 1995;22:151-4.

\section{LETTER}

Intense training in elite female athletes: evidence of reduced growth and delayed maturation? In their recent article Intensive training in elite young female athletes, Baxter-J ones and Maffulli reviewed 18 studies and concluded "training does not appear to affect growth and maturation." ${ }^{11}$ We have two concerns about this conclusion. Firstly, we agree that analyses of cross sectional and cohort data in this population are confounded by sampling bias; gymnasts who are successful at an elite level are likely to be self selected by their small stature and delayed maturation. Furthermore, data from cross sectional and cohort studies are often averaged. This "group" approach provides little information about individual growth patterns. Thus, in the review of Baxter-J ones and M affulli, and the literature at large, an important basic question has been overlooked: is there any evidence that growth and/or maturation are adversely affected in some athletes and if so, what is the frequency of this condition?

Secondly, in contrast with their findings, our analysis of over 35 clinical reports (cross sectional, historical, and prospective cohort studies) indicates that elite level gymnasts may be at risk of adverse effects on growth. ${ }^{2}$ We reported that the increased magnitude of the delay in skeletal maturation with training in adolescent female gymnasts, coupled with the occurrence of catch up growth during periods of reduced training or retirement, provides evidence that growth and maturation may be affected in some instances. ${ }^{23}$ Furthermore, in contrast with the interpretation made by Baxter-J ones and Maffulli of our data, we did report an association between reduced growth and years of gymnastic training, and that the deficits were greater at the axial than appendicular skeleton. ${ }^{3}$ We also reported that gymnasts who restricted energy intakes appeared to be at greatest risk.

We agree with Baxter-jones and Maffulli that a cause-effect relation between gymnastics training and inadequate growth of girls has not been shown; there have been no randomised controlled trials. However, this does not mean there is "no evidence for inadequate growth among female gymnasts." If clinicians are coerced by group means and ignore variability about the mean, then gymnasts who are at increased risk of reduced growth may be overlooked. We recommend that the growth of all young elite female gymnasts should be monitored regularly. Any gymnast who falls behind in growth-that is, across two major centiles of the growth chartshould undergo a complete evaluation for underlying pathology, even when height is not below the fifth centile. This may be normal short stature, but the clinical criterion warrants assessment.

S Bass, R Daly

School of Health Sciences, Deakin University, Burwood, Australia; shonab@deakin.edu.ac

D Caine

Department of Physical Education, Health and Recreation, W estern W ashington University, Bellingham, W ashington, USA

\section{References}

1 Baxter-J ones ADG, M affulli N . Intensive training in elite young female athletes. $\mathrm{Br}$ J Sports Med 2002;36:13-15.

2 Caine D, Lewis R, O 'Connor P, et al. Does gymnastics training inhibit growth of females? Clin J Sport Med 2001;11:260-70.

3 Bass S, Bradney M, Pearce G, et al. Short stature and delayed puberty in gymnasts: influence of selection bias on leg length and the duration of training on trunk length. Pediatr $2000 ; 136: 149-55$ 
BOOK REVIEW

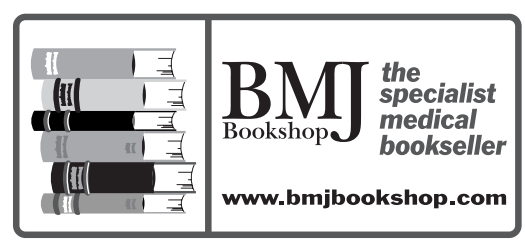

Spoilsports (understanding and preventing sexual exploitation in sport)

Celia H Brackenridge. Routledge-Taylor and Francis Books Ltd, 2001, $£ 19.99$, paperback pp 284. ISBN 0419257802

The book is targeted at everyone involved in sport: coaches, doctors, scientists, administrators, parents, and participants.

Celia Brackenridge is internationally acclaimed for her work in uncovering the story of sexual exploitation in sport and offering explanations about why it occurs. She is uniquely qualified by her professional expertise as a scholar in the sociology of sport and by her own experience as coach and athlete at elite level in the sport of lacrosse. It is very brave to pursue a line of research that almost always creates immediate resistance from the audience (" . . that can't be happening in our sport/profession"). It is also personally harrowing to investigate this issue with the victims and to find support to cope with what is heard. The production of this book is therefore a culmination of several years of difficult research. It is clear to me that all of us involved in sport must read this book and be aware of the issues. Those of us in higher education must also put this book on the reading list for "ethical issues" topics in curricula for all sport related degrees.

The title is great. Sport should be fun and run within a set of rules that are clear to all. But sexual exploitation within sport is a breach of rules and most certainly will spoil sport (and lives) for many (and who knows how many) individuals. The first two parts of the book provide evidence for the complex issue of sexual exploitation in sport and reasoning about why it may occur. If anyone reads this and continues to think that sexual exploitation cannot be happening in their sport or profession because there are no specific examples, then they must think again. Evidence suggests that exploitation will be happening in all areas of sport, and Brackenridge challenges us to become aware of that and then to take steps to prevent it. The third and fourth parts of the book offer a challenge to change the way sport is managed and how researchers can assist in this change in order that sexual exploitation is dealt with. This book is a brilliant example of "building bridges between theory and practice" (page 236) and utilises the feminist perspective of "praxis". (A definition of feminist praxis is "... the coming together of theory and practice in action, and in the reflecting upon these processes to generate new ideas and ways of working". ${ }^{1}$ ) The major message is that gender/power relations need to be examined in sport, and an empowerment based approach to sports leadership promoted.

Analysis

Presentation

Comprehensiveness

Readability

Relevance

Evidence basis

Total

$17 / 20$

$20 / 20$

$14 / 20$

$16 / 20$

$20 / 20$

$87 / 100$

$\mathrm{N}$ Mutrie

Department of Physical Activity and Health Science, University of G lasgow, Scotland, UK n.mutrie@bio.gla.ac.uk

\section{Reference}

1 Corin C. Feminist perspectives on politics. London: Longman, 1999:244

\section{CALENDAR OF EVENTS}

Sports Medicine Course

3-10 August 2002, Vancouver, Canada

Further details: Cathy Means; tel: +1608263 6637; fax: +1 608262 8421; email: cjmeans@facstaff.wisc.edu

\section{IEA World Congress of Epidemiology}

18-22 August 2002, M ontreal, Canada Further details: Conference Secretariat, Events International Meeting Planners, 759 Square Victoria, Suite 300, M ontreal, Quebec, H2Y 2] 7, Canada; tel: + 1514286 0855; fax: + 1514 286 6066; email: info@eventsintl.com Web site: www.iea2002.com

Kinesiology-New Perspectives. 3rd International Scientific

\section{Conference}

25-29 September 2002, Opatija, Croatia Further details: Conference Office, Faculty of Kinesiology, 10,000 Zagreb, Horvacanski zavo 15, Croatia; tel: + 38513658 666; fax: + 3581 3634 146; email: natalija.babic@ffk.hr

Evening Tutorials II: The ankle, anatomy, examination,

biomechanics, surgical

procedures, and rehab, with

practical sessions

Autumn 2002, Edinburgh

Further details: Dr Faith Gardner, 73a London Rd, Kilmarnock, Ayrshire; tel: (0) 1563537306

The Queen's Golden J ubilee and Post Commonwealth Games BASEM Congress 2002

10-13 October 2002, The Low Wood Hotel and Conference Centre, Windermere, Cumbria, UK

\section{Keynote lecturers}

Professor Stuart M McGill (Canada), will lecture on "Low back exercise: the foundation for building the best programme" and present a workshop on "a programme to enance spine stability". Assistant Professor Karim Khan (Canada), will lecture on "Better management of tendinopathies" and "Physical activity and bone health". Other speakers include Professor Dr med Hans H Paessler (Germany) lecturing on "Current concepts in knee ligament reconstruction following sports injuries" and "Rehabilitation after cruciate ligament reconstruction"; Mr Peter Hamlyn (United Kingdom), Chairman of the Government Ministerial Working Group Report on
Saftey and Medicine in Sport, will open and Chair a discussion on progress one year on from the report.

A full programme is available on our web site www.bjsportmed.com.

Further details: Mrs Sue Roberts, BASEM Company Office, 12 Greenside Ave, Frodsham, Cheshire WA6 7SA, UK; tel/fax: + 44 (0) 1928 732 961; email: basemoffice@ compuserve.com

Web site: www.basem.co.uk

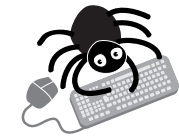

Please visit our website for a full programme.

Sports Medicine of Australia 2002 Australian Conference

12-16 October 2002, Carlton Crest Hotel, M elbourne, Australia

Keynote speakers include Dr Bill Evans, Professor Tom Rowland, and Dr Glenn Singleman.

Further details: Kate Gulliver, Sports M edicine Australia, PO Box 237, Dickson ACT 2602; tel: +02 6230 4650; fax: +02 6230 5908; email: sma.conf@sma.org.au; Carlton Crest Hotel contact details: 65 Queens Road, M elbourne VIC 3004, Australia; tel: + 6139526 7470; fax: +61395267400.

\section{Celebrating 50 years of Orthopaedics in Singapore}

13-16 October 2002, Singapore

In conjunction with the 25th Singapore Orthopaedic Association Meeting, 22nd Asean Orthopaedic Association M eeting, 5th Combined Meeting of Spinal and Paediatric Sections-APOA, 7th M eeting of Sports M edicine Section-APOA, 3rd Meeting of Asiapacific Orthopaedic Society for Sports Medicine.

Further details: 2002 COM Secretariat, c/o Dept of Orthopaedic Surgery, National University Hospital, 5 Lower Kent Ridge Road, Singapore 119074, Republic of Singapore; tel: +65 772 4340; fax: +65 778 0720; email: secretariat@soa.org.sg

Web site: http://orthopaedics2002. calendarone.com

\section{BASICS Immediate Care Course}

21-25 October 2002, Madingley Hall, Cambridge, UK

This five day residential course is primarily aimed at those with extensive experience in immediate care, this course will develop and enhance the necessary skills to deal with all medical and other emergencies in prehospital medicine.

Further details: BASICS Education Ltd; tel : +44 (0) 870165 4999; fax: + 44 (0)870 165 4949; email: educ@basics.org.uk

Web site: www.basics.org.uk

\section{BASICS Immediate Care Course} "Top up"

24-25 October 2002, Madingley Hall, Cambridge, UK

This two day course is for those who would like to attend the final two days of the Immediate Care Course to develop their skills. 
Further details: BASICS Education Ltd; tel: + 44 (0) 870165 4999; fax: + 44 (0)870165 4949; email: educ@ basics.org.uk

Web site: www.basics.org.uk

\section{The 5th Asian Federation of} Sports Medicine Congress

24-27 October 2002, Seoul, South Korea Further details: AFSM C 2002 Seoul Secretariat, Hanjim Travel Service Co Ltd, (c/o Young CHANG) Marine Center New Bldg 5th $\mathrm{Fl}$ \#51, Sogong-dong, Chung-gu, Seoul 100-770, South Korea; tel: +822 726 5555; fax: +822

778 2514; email: ychang@ kaltour.com

Web site: http://www.afsmc2002.or.kr

\section{Australian College of Sports}

Physicians (ACSP) 2002

Conference in conjunction with

the New Zealand Sports

Medicine Conference

30 October-3 November 2002, Christchurch,

$\mathrm{NZ}$

Keynote speaker will be Assistant Professor Karim Khan from Vancouver, Canada.

Further details: Rob Campbell; email rcampbell@sportsmed-nz.co.nz

Web site: www.acsp.com.au

\section{Skills Course in Musculoskeletal} Ultrasound

6-8 J anuary 2003, Oxford, UK

Further details: Alison Davies, Department of Radiology, Nuffield Orthopaedic Centre, Headington, Oxford, OX3 7LD, UK; tel: +44 (0) 1865 227765; fax: +44(0) 1865227347 email: alison.davies@noc.anglox.nhs.uk

\section{BASICS Refresher course}

28-29 November 2002, M adingley Hall, Cambridge, UK

This two day course is directed at previous participants on the pre-hospital emergency care and immediate care courses. The aim is to maintain and update skills, incorporating the latest developments in pre-hospital care.

Further details: BASICS Education Ltd; tel: + 44 (0) 870165 4999; fax: + 44 (0) 870165 4949; email: educ@basics.org.uk

Web site: www.basics.org.uk

\section{2nd World Congress of Science} and Medicine in Cricket

4-7 February 2003, University of Port Elizabeth, South Africa

Further details: Dr Richard Stretch, University of Port Elizabeth, PO Box 1600, Port Elizabeth 6000, South Africa; tel: +2741 5042584; fax +27 41 5832605; email: sparas@upe.ac.za

\section{Vth World Congress on Science} $\&$ Football

April 2003, Lisbon, Portugal

Further details: $\mathrm{Dr} J$ Cabri; email: J cabri@fmh.utl.pt

Web site: http://www.fmh.utl.pt/wesf 3rd Québec International Symposium on Cardiopulmonary Rehabilitation Evidence Based Interventions: Science to the Art of Cardiopulmonary

Rehabilitation

11-13 May 2003, Québec City Convention Center, Québec, Canada

Call for abstracts deadline is 1 November 2002. The abstract submission form and complete programme can be printed from the web site.

Further details: email: J ean.J obin@

med.ulaval.ca

Web site: www.ulaval.ca/symp-rehab

The 6th STMS World Congress on Medicine and Science in Tennis in conjunction with the LTA 2004 Sports Science, Sports Medicine and Performance

Coaching Conference

19-20 J une 2004, London, UK

Keynote speakers include Professor Per Renstrom (SWE), Professor Peter Jokl (USA),

Professor Savio Woo (USA), Dr Carol Otis (USA), Dr M ark Safran (USA), Dr Ben Kibler (USA), Prof Bruce Elliott (AUS), and Professor Ron Maughan (UK).

Further details: Dr Michael Turner, The Lawn Tennis Association, The Queen's Club, London W14 9EG, United Kingdom; email michael.turner@LTA.org.uk

\section{NOTES AND NEWS}

Diploma in Sport and Exercise Medicine for Great Britain and Ireland

Details for the above exam can be found on the Royal College of Surgeons of Edinburgh Website at http://www.rcsed.ac.uk alternative applicants can write to: The Royal College of Surgeons of Edinburgh, Eligibilities Section, Careers Information Services, 3 Hill Place, Edinburgh; tel: + 44 (0) 1316689222 or M rs Yvonne Gilbert, Intercollegiate Academic Board for Sport and Exercise M edicine, Royal College of Surgeons of Edinburgh, Nicolson Street, Edinburgh EH8 9DW; tel: + 44 (0)131 527 3409; email: y.gilbert@ rcsed.ac.uk

\section{www.basem.co.uk}

The British Association of Sport and Exercise Medicine has launched its new websitewww.basem.co.uk. The site provides information about the educational opportunities in sport and exercise medicine and advice to those wishing to become involved in this area.

Interested in Sports Medicine?

Gain a higher degree from

Australia's leading University

The Centre for Sports M edicine Research and Education is a multidisciplinary Centre Io- cated in the Faculty of Medicine, Dentistry and Health Sciences at the University of M elbourne, Australia. It combines world-class researchers and clinicians working in the area of sports medicine.

Research Higher Degrees

The Centre offers Doctor of Philosophy (PhD), Master of Sports M edicine, M aster of Physiotherapy, Master of Science, and Doctor of Medicine degrees. These are available to graduates of health and medical science courses such as physical therapy, medicine and human movement.

Educational programme

The Centre offers a one month full time Postgraduate Certificate in Sports Physiotherapy: spine, pelvis, and lower limb. Instructors are leading clinical experts and researchers in the multidisciplinary approach to sports medicine. The Certificate will run from Nov 4-29 in 2002.

Please contact: A/Professor Peter Brukner: p.brukner@unimelb.edu.au (Research Degrees), A/Professor Kim Bennell: k.bennell@ unimelb.edu.au (Research Degrees), M r Henry Wajswelner: h.wajswelner@unimelb.edu.au (Certificate Courses).

www.physioth.unimelb.edu.au/csmre

Sports medicine at the University of New South Wales

Masters of Sports M edicine

You don't have to leave your practice:

- Delivery by distance education

- Videos, CD-ROM s and online learning

- All aspects of Sports M edicine covered

- Locally organised examinations

- Clinical training

- Certificate and Diploma courses also offered

Further details: Sports Medicine Programs, UNSW Sydney 2052, Australia; tel: +612 9385 2557; fax: +612 9313 8629; email: sportsmed@unsw.edu.au

Web site: www.med.unsw.edu.au/sportsmed

\section{NCPAD NEWS}

A monthly publication of the National Center on Physical Activity and Disability. NCPAD is the leading source for information about organisations, programmes, and facilities nationwide providing accessible physical activity and recreation. NCPAD also has a large and growing online library of fact sheets, monographs, and contact information on physical activity and recreation for people with disabilities.

Sign up for this free monthly electronic newsletter by sending an email to: Listserv@listserv.uic.edu, with this message in the body of the e-mail: SUBSCRIBE NCPAD-NEWS yourfirstname yourlastname. If you have any difficulty, you can also sign up for the newsletter by going to http:// www.ncpad.org/signup 